\title{
Análise multitemporal de uso e ocupação do solo do núcleo inicial do projeto integrado de colonização Paulo de Assis Ribeiro no município de Colorado do Oeste - RO
}

\section{Multitemporal analysis of soil use and occupation of the initial core of the integrated project of colonization Paulo de Assis Ribeiro in the municipality of Colorado do Oeste - RO}

Danielle Ivana Pereira dos Santos Instituto Federal de Educação, Ciência e Tecnologia de Rondônia Campus de Colorado do Oeste Rodovia 399, Km 05 - Zona Rural danielle_ivana@hotmail.com

Érica de Oliveira Araújo Instituto Federal de Educação, Ciência e Tecnologia de Rondônia Campus de Colorado do Oeste Rodovia 399, Km 05 - Zona Rural erica.araujo@ifro.edu.br

Pâmela Cristina Patrício Pagani ${ }^{1}$ Instituto Federal de Educação, Ciência e Tecnologia de Rondônia Campus de Colorado do Oeste Rodovia 399, Km 05 - Zona Rural pamelapagani@hotmail.com

Caio Henrique Patrício Pagani

Universidade Federal do Amazonas Instituto de Educação, Agricultura e Ambiente Rua 29 de Agosto, 786, Divino Pranto caiopagani@gmail.com

Marcel Eméric Bizerra de Araújo Instituto Federal de Educação,Ciência e Tecnologia de Rondônia

Campus de Colorado do Oeste Rodovia 399, Km 05 - Zona Rural marcel.emeric@ifro.edu.br

Marcelo Pires Negrão Université Sorbonne Nouvelle Centre de Rechercheet de Documentation des Amériques Rua 28, Saint-Guillaum, Paris negrãobr@uol.com.br

Artigo recebido para revisão em 26/07/2014 e aceito para publicação em 03/10/2014

\section{Resumo}

A área de estudo corresponde a 32\% de um total de 293.580 ha $^{-1}$ do Projeto Integrado de Colonização (PIC) Paulo de Assis Ribeiro em Rondônia. Durante quase quatro décadas (1981 a 2010) esta área esteve sujeita a várias mudanças em seus padrões de uso e ocupação do solo, as quais foram registradas por imagens orbitais. Assim, objetivou-se com o presente trabalho analisar e quantificar o uso e ocupação do solo do núcleo inicial do projeto integrado de colonização Paulo de Assis Ribeiro - PICPAR, localizado no município de Colorado 
do Oeste em Rondônia durante o período de 1981 a 2010. Os resultados obtidos permitiram concluir que ao longo do período (1981-2010), houve perda de cerca de 70\% da cobertura vegetal natural, averiguando-se, principalmente, a conversão da floresta em pastagem. Além disso, pode-se dizer que a classificação na área estudada apresentou desempenho entre razoável e excelente $(0.58$ a 0.86$)$ isso significa que a classificação das imagens aproximou-se razoavelmente da realidade do campo.

Palavras-chave: Geotecnologia; Sensoriamento remoto; Uso e ocupação do solo; PIC; Rondônia.

\begin{abstract}
The study area corresponds to $32 \%$ of a total of $293.580 \mathrm{ha}^{-1}$ of the Integrated Project of colonization (PIC) Paul Daniell in Rondônia. During nearly four decades (1981 to 2010) this area was subject to several changes in their patterns of use and occupation of the soil, which were recorded by orbital images. Thus, the objective of the present work to analyze and quantify the soil use and occupation of the initial core of the integrated project of colonization Paul Daniell-PICPAR, located in the municipality of Colorado do Oeste in Rondônia during the period of 1981 to 2010. The results obtained allowed to conclude that over the period (1981-2010) there was loss of about $70 \%$ of the natural vegetation cover, checking mainly the conversion of forest into pasture. In addition, it can be said that the classification in the area studied showed reasonable performance and excellent ( 0.58 to 0.86 ) this means that the classification of images approached reasonably of the reality of the field.
\end{abstract}

Keywords: Geotechnology; Remote sensing; Soil use and occupation; PIC; Rondônia.

\title{
1. INTRODUÇÃO
}

A derrubada de florestas na região amazônica para produção agrícola e pecuária teve seu início na década de 70. As causas históricas e presentes são diversas e freqüentemente interrelacionadas (SOARES FILHO et al., 2005). Segundo, Théry (1997) a coincidência entre os desmatamentos e a abertura das estradas é, então, total, pois são ao mesmo tempo causa e consequência. Com a abertura da rodovia BR 364, ligando as cidades de Cuiabá e Porto Velho intensificou-se o desmatamento no estado de Rondônia. E, em decorrência disso, propiciou elevados índices migratórios e a mais alta taxa de crescimento demográfico anual (CORREA et al., 2006).

Contudo, para Noronha et al. (2010) apenas recentemente o desmatamento nessa região tem se transformado foco das atenções internacionais, as quais alimentam críticas acerca da perda de biodiversidade e do potencial de contribuição para mudanças climáticas, entre outros aspectos.

Embora a legislação ambiental brasileira seja uma das mais completas e modernas entre os países sul-americanos (ROCHA et al., 2005), muito de seus instrumentos têm se revelado inadequados para protegê-la. A explicação mais recorrente é a falta de recursos financeiros e humanos para fiscalização.

Em face da realidade econômica do Brasil, o geoprocessamento surge como alternativa viável para os estudos ambientais, sobretudo, no monitoramento da mudança da cobertura vegetal da região amazônica, com destaque para o estado de Rondônia. Entende-se por geoprocessamento, o conjunto de tecnologias que englobam diversas fases, desde a coleta, o processamento, a análise, 
até a disponibilização de informações, cujo resultado é apresentar referencial geográfico (MARTINS; RODRIGUES, 2012). Dentre as geotecnologias podem-se destacar os sistemas de informação geográfica, a cartografia digital, o sensoriamento remoto e o sistema de posicionamento global (ROSA, 2005).

Atualmente, na literatura são relatados inúmeros trabalhos que se valem das "geotecnologias" em diversos campos da ciência, e que exploram diferentes objetivos. O uso e a ocupação do solo em escalas multitemporais, o diagnóstico de áreas susceptíveis à erosão, a caracterização e análise de bacias hidrográficas e a utilização dos modelos digitais do terreno para análises geomorfológicas têm sido descrito por vários autores (AZEVEDO et al., 2014; RIBEIRO, 2006; HOFF et al., 2008; GOIS, 2010). Assim, os estudos ambientais baseados em metodologias que consideram como ferramenta auxiliar o uso de "geotecnologias" permite a manipulação e a organização de grande volume de dados e informações espaciais e tabulares, possibilitando, inclusive, a obtenção de novas informações interpretativas a partir de modelos. Adicionalmente, Rosot et al. (2008) enfatizam que tais abordagens permitem a transformação do dado espacial e das geotecnologias em ferramentas de apoio à gestão e à tomada de decisão. Além disso, a avaliação dos mapas gerados possibilita o acompanhamento temporal das transformações ocorridas em um determinado intervalo de tempo.

Considerando essas premissas, objetivou-se com o presente trabalho, a partir de técnicas de geoprocessamento, analisar e quantificar o uso e ocupação do solo do núcleo inicial do projeto integrado de colonização Paulo de Assis Ribeiro - PICPAR, localizado no município de Colorado do Oeste em Rondônia durante o período de 1981 a 2010.

\section{MATERIAL E MÉTODOS}

\section{1. Área de estudo}

A área de estudo localiza-se ao sul do estado de Rondônia, na microrregião de Colorado do Oeste a aproximadamente $700 \mathrm{~km}$ da capital Porto Velho. A área localiza-se na porção leste da microrregião entre as coordenadas geográfica de latitude $13^{\circ} 13^{\prime} 00^{\prime \prime} \mathrm{S}$ e $60^{\circ} 47^{\prime} 51^{\prime \prime} \mathrm{W}$ e abrange parte dos municípios de Cabixi, Cerejeiras, Corumbiara, Pimenteiras do Oeste e Colorado do Oeste (Figura 1). 


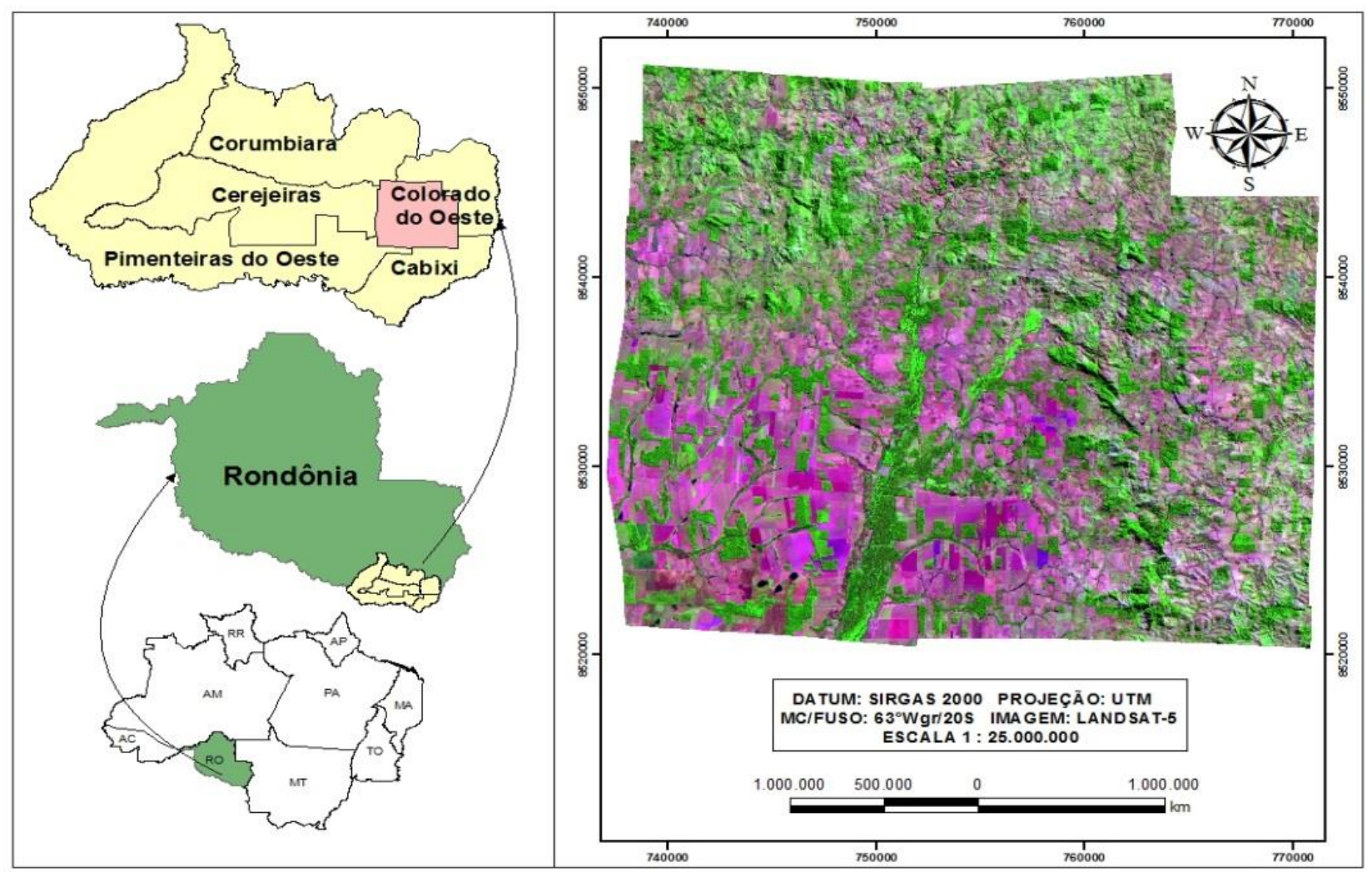

Figura 1- Mapa de localização do núcleo inicial do projeto integrado de colonização Paulo de Assis Ribeiro PICPAR, localizado no município de Colorado do Oeste em Rondônia, 2010.

O clima da região é do tipo Aw, tropical chuvoso, com duas estações bem definidas uma chuvosa (outubro a abril) e a outra seca (maio a setembro), segundo a classificação de Köppen. A temperatura média anual é de $24^{\circ} \mathrm{C}$, a máxima de $36^{\circ} \mathrm{C}$ e a mínima de $12^{\circ} \mathrm{C}$, com precipitações superiores a $2.200 \mathrm{~mm}$ anuais (LIMA et al., 2011).

Dal Magro et al. (2010) relatam que dentre os tipos de solo identificados, destacam-se os Solos Aluviais que caracterizam-se por ser solos minerais, não hidromórficos, pouco desenvolvidos e originados de sedimentos aluviais não consolidados. Tais solos possuem argila de atividade baixa e textura argilosa, siltosa ou franca. Geralmente são solos férteis, porém, as más condições de drenagem e as frequentes inundações limitam a sua utilização agrícola. Eventualmente são usados com pastagem extensiva e cultivo de milho e soja, por exemplo, conforme se constata in loco. Contudo, o solo predominante da área experimental é do tipo Argissolo Vermelho Eutrófico (EMBRAPA, 2013).

\subsection{Breve histórico de ocupação da região}

A colonização da Amazônia iniciou-se a partir da década de 1970 sob regência do autoritarismo militar. Uma das estratégias adotadas foi à implementação de políticas de integração, a qual visava garantir a ocupação da região, expandir os mercados e servir como escape para os 
problemas no campo, os quais se avolumavam em outras regiões do país (LISBOA, 2013). Admitese que este contexto político e econômico, aliado à conclusão da rodovia Cuiabá - Porto Velho direcionaram a implementação dos projetos de colonização dirigidos cuja finalidade era promover a utilização integrada das potencialidades agropecuárias, florestais, agroindustriais e minerais.

Os Projetos de Colonização foram instalados, majoritariamente, em duas categorias: os oficiais, executados pelo governo e, os de colonização de iniciativa particular. Segundo Moser (2008), este último era realizado por empresas particulares de colonização cadastradas no Instituto de Colonização e Reforma Agrária - INCRA em terras particulares ou públicas, porém em Rondônia predominou amplamente a Colonização Oficial, conforme o modelo denominado Projeto Integrado de Colonização (PIC) em áreas cortadas pelas rodovias Transamazônica e Cuiabá Santarém.

Como conseqüência, pôde ser observada um grande deslocamento populacional em direção a Rondônia, uma vez que na década de 1980 seu contingente demográfico quadruplicará. Nesse sentido, o INCRA expandiu as atividades de assentamento com novos PIC's como o Paulo de Assis Ribeiro, no qual estava previsto o assentamento de 3.656 famílias em $293.580 \mathrm{ha}^{-1}$. Nessas circunstâncias emergiram cinco novos municípios: Cabixi, Cerejeiras, Pimenteiras do Oeste, Corumbiara e o núcleo principal, Colorado do Oeste (RABELLO; FERREIRA, 2005).

\section{MATERIAIS UTILIZADOS}

- GPS Garmin 76 CSx;

- Software TrackMarker 4.8 Pro;

- Software ArcGIS 10.2;

- Imagem do sensor remoto Landsat-5 (Tabela 1).

Tabela 1- Imagens utilizadas para análise multitemporal da área de estudo.

\begin{tabular}{ccccc}
\hline Satélite & Sensor & Data do Imageamento & Rota/Cena & Acervo \\
\hline LANDSAT-2 & MSS & $09 / 07 / 1981$ & $247 / 69$ & \\
LANDSAT-5 & TM & $13 / 06 / 1985$ & $230 / 69$ & \\
LANDSAT-5 & TM & $13 / 07 / 1990$ & $230 / 69$ & Catálogo de Imagens do INPE \\
LANDSAT-5 & TM & $27 / 07 / 1995$ & $230 / 69$ & $230 / 69$ \\
LANDSAT-5 & TM & $08 / 07 / 2000$ & $230 / 69$ & \\
LANDSAT-5 & TM & $22 / 07 / 2005$ & $230 / 69$ & \\
LANDSAT-5 & TM & $04 / 07 / 2010$ & \\
\hline
\end{tabular}

Fonte: INPE, 2013.

\section{PROCEDIMENTOS METODOLÓGICOS}

A coleta de pontos de amostragem de uso e ocupação de solo foi realizada em condição de campo, com visita a propriedade rural Lote 18 (sítio Estrela), no município de Colorado do Oeste - 
Rondônia, cujas coordenadas geográficas são latitude $13^{\circ} 09^{\prime} 57^{\prime}$ ' S, longitude $60^{\circ} 37^{\prime} 44^{\prime \prime}$ W, e altitude média de 372 metros (Figura 7). Para tanto, utilizou-se o GPS Garmin modelo 76 CSx. Os dados foram descarregados no software TrackMarker 4.8 Pro, sendo posteriormente, exportados e processados no ArcGIS 10.2.

As imagens foram adquiridas através de satélite Landsat5ThematicMapper - LANDSATTM, em formato digital (Tabela 1). Essa escolha ocorreu em decorrência das características de registros multiespectrais com alta resolução espacial, em razão da maior sensibilidade dos seus sensores e à possibilidade de obterem-se imagens compostas coloridas, permitindo uma interpretação mais rápida e fiel do tema em questão e um melhor monitoramento das ações antrópicas das áreas "imageadas" pela disponibilidade e a repetibilidade das imagens (OKA-FIORI et al., 2003). A metodologia de interpretação de imagens consistiu nas seguintes etapas de estudo:

1. Seleção de cartas com mínimo de cobertura de nuvens na área de estudo;

2. Composições coloridas das imagens na conformação RGB (TM4 TM5 TM3), com posterior recorte da imagem mediante uso da shape de 1038 lotes rurais da base fundiária da Secretaria do Estado do Desenvolvimento Ambiental - SEDAM em Rondônia.

3. Classificação supervisionada por "MaximumLikelihood”, usando as classes: água, solo exposto, floresta, pastagem, queimadas e não-classificada.

4. Foram distribuídos aleatoriamente 150 pontos amostrais por meio de "Create Random Point"contida do pacote computacional ArcGis 10.2. Dessa forma, gerou-se a matriz de confusão entre a referência, ou seja, a imagem RGB (TM4 TM5 TM3) e o classificador (Máxima Verossimilhança). Embora, Arraes e seus colaboradores (2010) afirmem que essa comparação deva ser feita com a verdade terrestre, tal situação torna-se dispensável em detrimento dos padrões florestais e outros usos (não florestais) serem amplamente conhecidos e essas classes deterem respostas espectrais distintas.

\subsection{Determinação do desempenho global, índice Kappa}

A partir dos valores obtidos pela matriz de confusão é possível determinar a acurácia global (Equação 1).

$$
A G=\frac{D}{T}(1)
$$

Em que:

$\mathrm{AG}=$ Acurácia global;

$\mathrm{D}=$ Somatório dos elementos da diagonal principal;

$\mathrm{T}=$ Número total de pontos. 
O índice Kappa é uma medida de concordância de dados categóricos, desenvolvido por Cohen (1960), que permite comparar as classificações obtidas automaticamente coma verdade de campo (referência). Varia de 0 a 1 , e os dados serão mais acurados quanto mais o índice se aproximar de 1 (AZEVEDO, 2013). O IK pode ser representado pela Equação 2.

$$
I K=\frac{(D-Q)}{(T-Q)}
$$

Sendo:

IK = Índice Kappa;

$\mathrm{D}=$ Somatório dos elementos da diagonal principal;

$\mathrm{Q}=$ Coeficiente entre o erro de comissão e o erro de omissão;

$\mathrm{T}=$ Número total de pontos.

\section{RESULTADOS E DISCUSSÕES}

\subsection{Uso e ocupação do solo}

A classificação supervisionada por meio do MaximumLikelihood, segundo trabalho de Latorre et al. (2007) é uma ferramenta que possibilita separar as classes temáticas, sobretudo, floresta e solo exposto, visto que o comportamento espectral desses dois alvos são bem diferentes na banda $3(0.63-0.69 \mu \mathrm{m})$, região do vermelho do sensor TM, no qual a vegetação apresenta a cor verde, densa e uniforme, detêm grande absorção, ficando escura e permitindo bom contraste entre as áreas que se apresentam com solo exposto, estradas e áreas urbanas (ARRAES et al., 2010). As imagens classificadas e dispostas nas figuras 2 e 3 permitem uma boa compreensão da dinâmica de uso e ocupação do núcleo inicial do Projeto Integrado de Colonização Paulo de Assis Ribeiro PICPAR. Após classificá-las, determinou-seas áreas das respectivas classes temáticas conforme a Tabela 2.

Tabela 2 - Projeto Integrado de Colonização Paulo de Assis Ribeiro - PICPAR - Núcleo Inicial, Município de Colorado do Oeste - Rondônia. Áreas das Classes de Uso e Ocupação do Solo - Série Multitemporal.

\begin{tabular}{lrrrrrrr}
\hline \multicolumn{1}{c}{ Classes } & \multicolumn{1}{c}{$\mathbf{1 9 8 1}$} & $\mathbf{1 9 8 5}$ & $\mathbf{1 9 9 0}$ & $\mathbf{1 9 9 5}$ & $\mathbf{2 0 0 0}$ & $\mathbf{2 0 0 5}$ & $\mathbf{2 0 1 0}$ \\
\cline { 2 - 7 } & \multicolumn{7}{c}{ Área em Hectares (ha) } \\
\hline Água & 218,21 & 739,57 & 710,23 & 280,06 & 425,31 & 193,85 \\
Solo Exposto & $12.507,15$ & $14.316,43$ & $36.696,45$ & $36.793,02$ & $50.581,72$ & $42.483,30$ & $43.264,50$ \\
Floresta & $81.080,51$ & $74.729,31$ & $53.739,23$ & $44.526,51$ & $35.965,35$ & $28.643,66$ & $23.761,42$ \\
Pastagem & 167,66 & $3.781,71$ & 970,13 & $10.996,75$ & $4.307,72$ & $20.855,89$ & $25.489,39$ \\
Queimada & - & 7,02 & $1.065,43$ & 899,12 & $2.344,15$ & $1.326,32$ & 332,35 \\
Não & 270,04 & 669,55 & $1.062,10$ & 748,12 & 619,33 & 740,56 & 113,21 \\
Classificado & & & & & & & \\
\hline
\end{tabular}


Ao analisar as imagens classificadas para os anos de 1981 (Figura 2) pode-se inferir que houve uma inexpressiva intervenção antrópica. Trata-se, na realidade, do período da abertura das vicinais ou linhas, as quais possuíam em média quinze metros de largura. Na imagem de 1985 observa-se que houve um aumento na área desmatada o que pode ser atribuída a efetiva ocupação do assentamento, uma vez que o PICPAR contabilizava somente uma década de existência. O modelo de assentamento adotado pelo INCRA seguiu o padrão retangular ou, numa linguagem dos assentados, o "quadrado burro", no qual as casas ficavam a quilômetros de distância umas das outras.

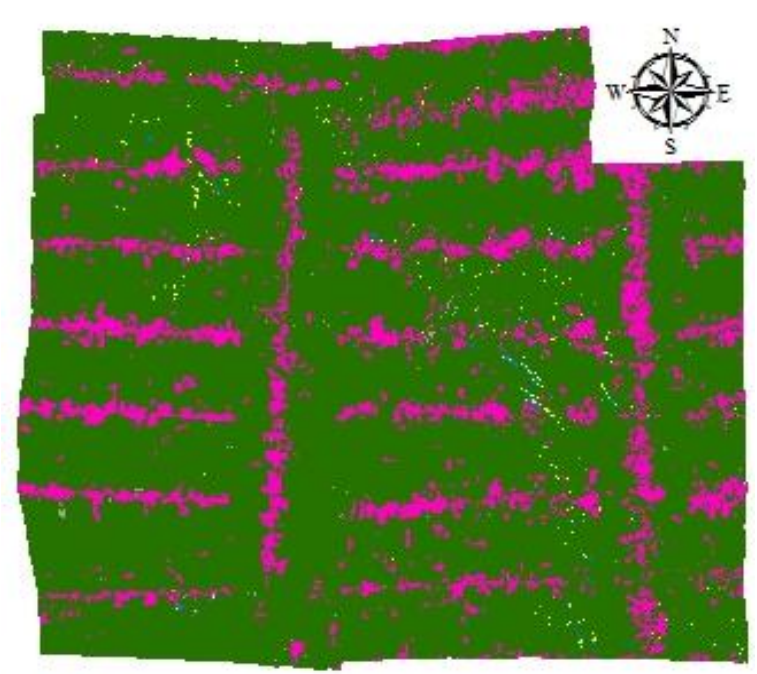

1981

\section{Classes de uso do solo}

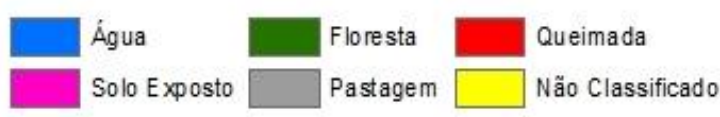

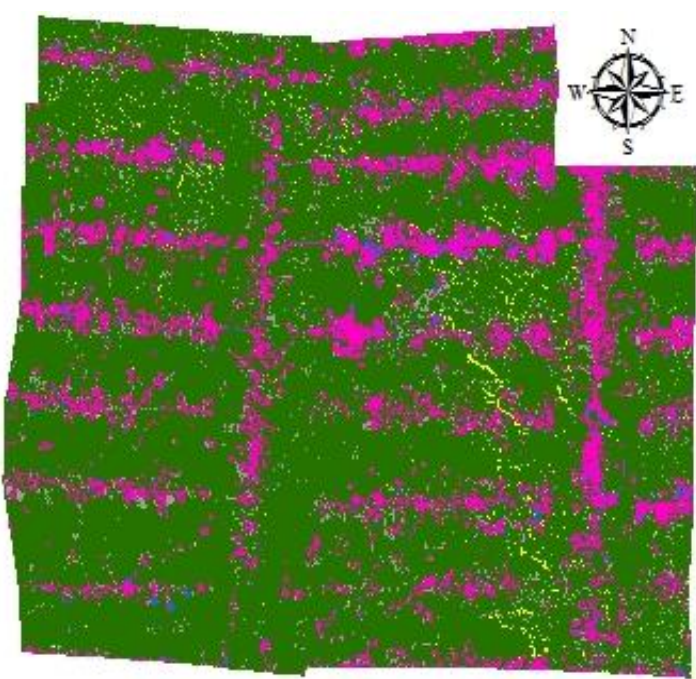

1985

Escala $1: 400.000$

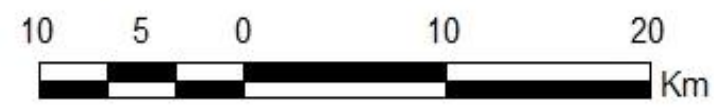

Figura 2 - Evolução têmporo-espacial do desmatamento no núcleo inicial do Projeto Integrado de Colonização Paulo de Assis Ribeiro - PICPAR, localizado no município de Colorado do Oeste em Rondônia nos anos de 1981 e 1985.

Na segunda metade dos anos de 1980 estendendo-se até 1995, conforme pode ser visualizado nas figuras 3 e 4, observa-se um cenário bastante modificado, pois o processo de ocupação não se baseou em estudo técnico-científico ou em planejamento prévio adequado, o que por si só denota falhas com reflexos de toda ordem no meio físico-biológico e socioeconômico, a exemplo de processos erosivos, perda de biodiversidade e, sub-aproveitamento agropecuário, baixa produtividade, entre outros. Nesse sentido, o desmatamento foi à principal conseqüência imediata, crescendo vertiginosamente e colocando em evidência mudanças relativamente rápidas experimentadas na área em questão. Uma nova paisagem surge no cenário. 


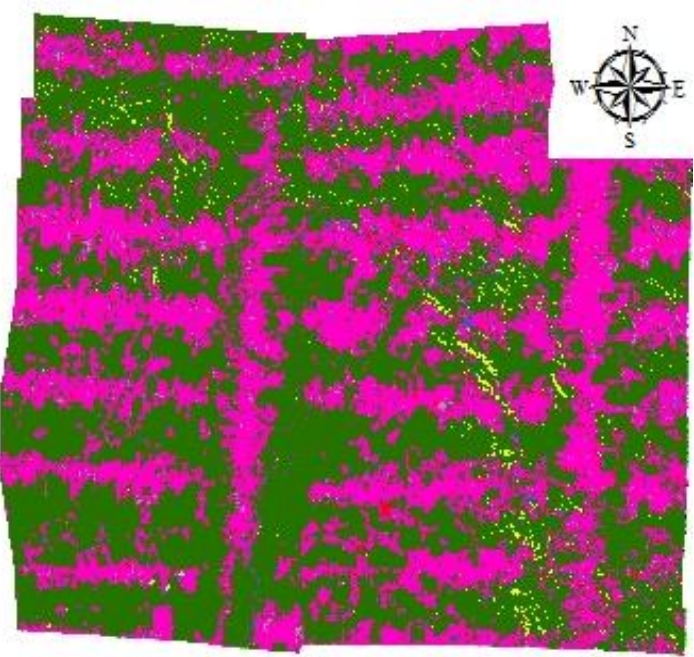

1990

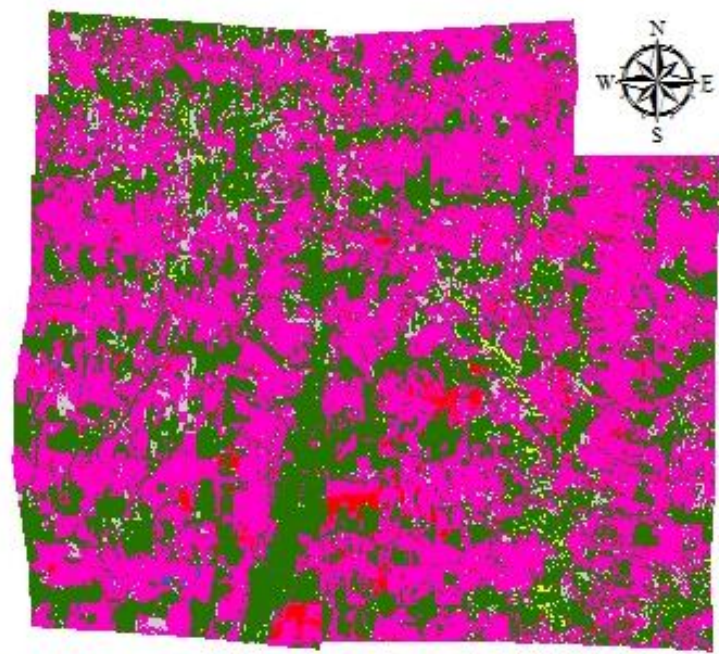

2000

Classes de uso do solo

\begin{tabular}{l|l} 
Água & Floresta $\square$ Queimada \\
Solo Exposto & Pastagem $\square$ Não Classificado
\end{tabular}

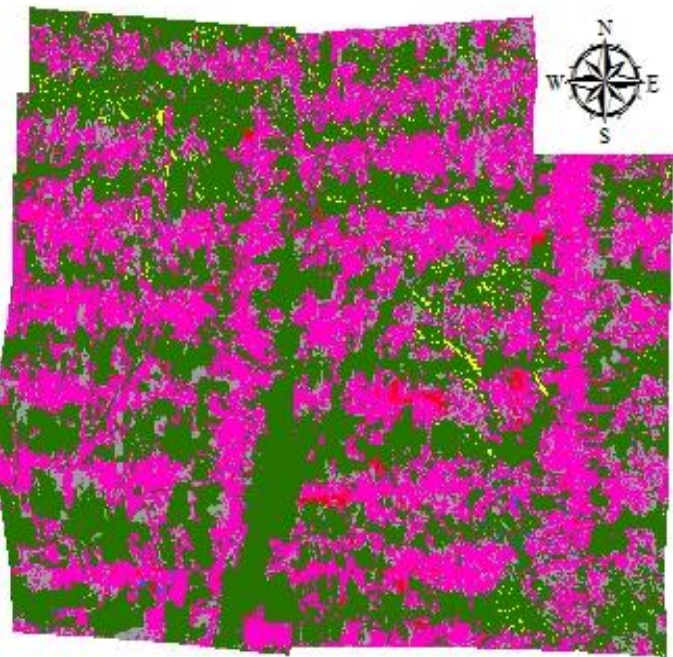

1995

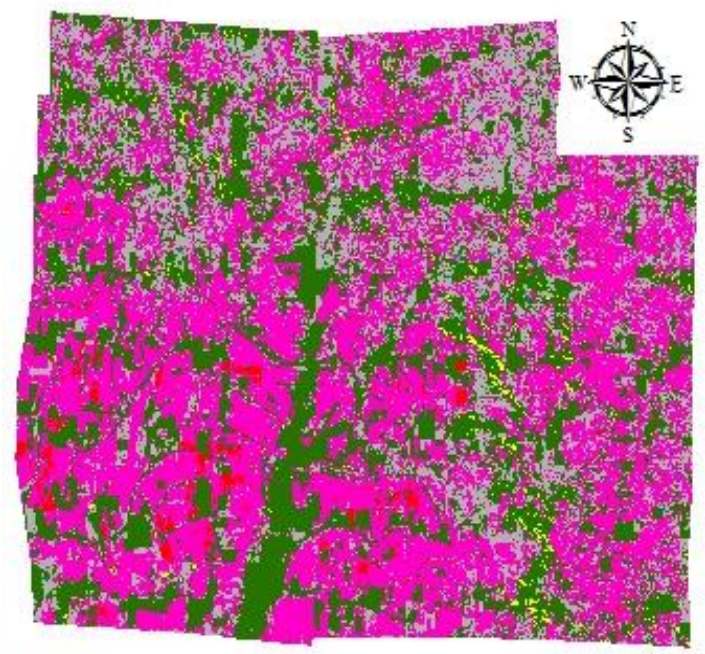

2005

Figura 3 - Evolução têmporo-espacial do desmatamento no núcleo inicial do Projeto Integrado de Colonização Paulo de Assis Ribeiro - PICPAR, localizado no município de Colorado do Oeste em Rondônia nos anos de 1990, 1995 e 2000 e 2005. 

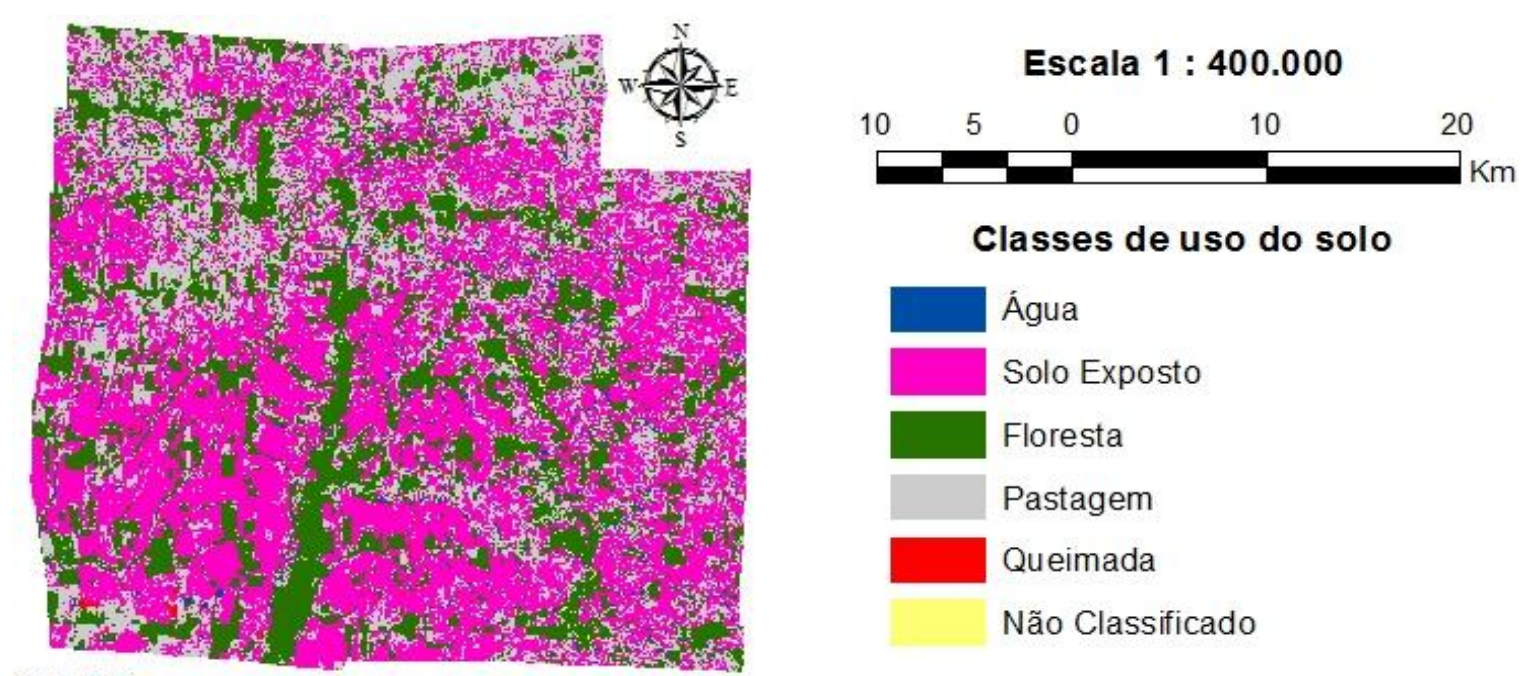

\section{0}

Figura 4 - Evolução têmpora-espacial do desmatamento no núcleo inicial do Projeto Integrado de Colonização Paulo de Assis Ribeiro - PICPAR, localizado no município de Colorado do Oeste em Rondônia no ano de 2010.

A figura 5, por sua vez, demonstra que em 1981, a vegetação natural ocupava $86.03 \%$ do total da área. Quatro anos depois, ou seja, em 1985, esta área diminui para 79.29\%. Nos anos seguintes observou-se a mesma dinâmica para a classe floresta, ou seja, um contínuo decréscimo da cobertura vegetal nativa, haja vista que em 2010 estas representava somente $25.21 \%$ (Figuras 5 e 6). Com base nos dados obtidos é possível conjecturar que houve um decréscimo de aproximadamente $57.319,09$ hectares nestas três últimas décadas, o que corresponde à perda de cerca de $70 \%$ da cobertura vegetal natural.

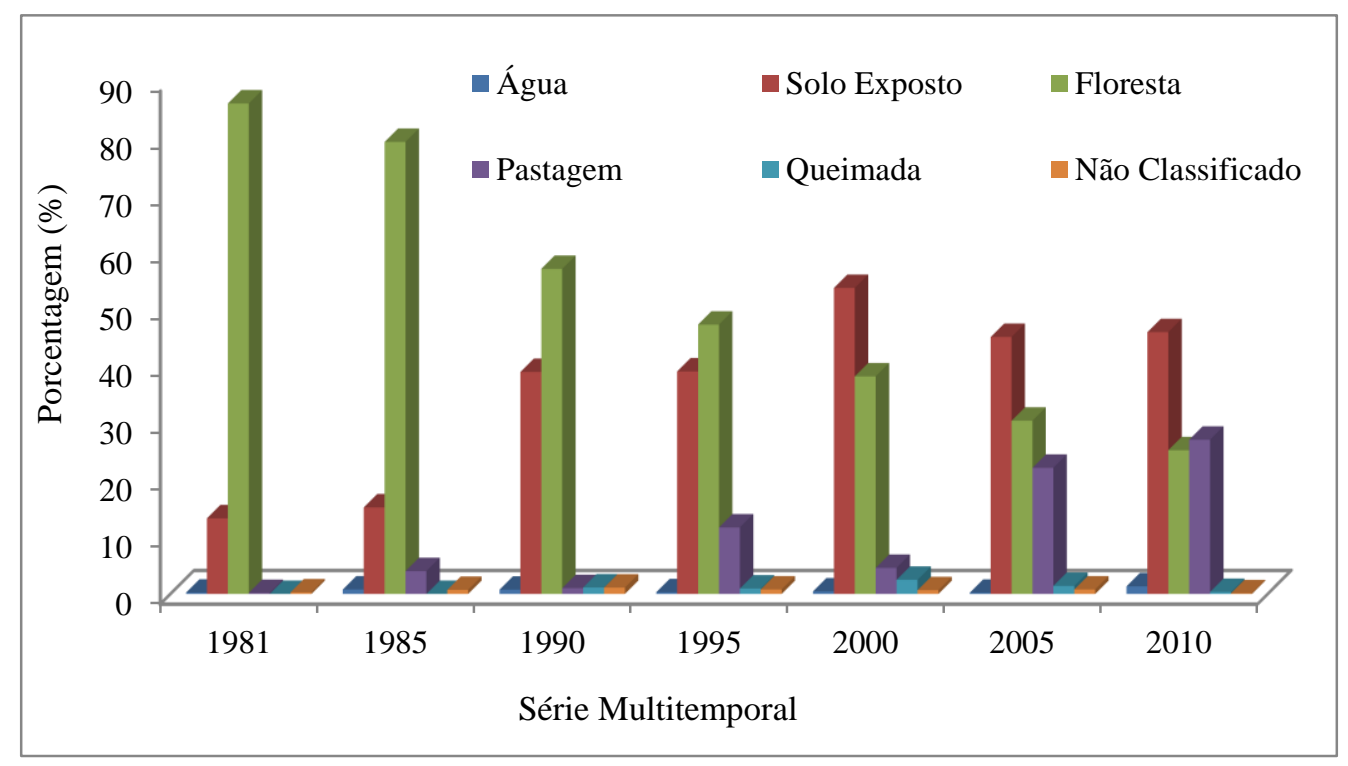

Figura 5 - Histograma da variação das diversas classes de uso e ocupação no núcleo inicial do Projeto Integrado de Colonização Paulo de Assis Ribeiro - PICPAR, localizado no município de Colorado do Oeste em Rondônia no período de 1981 a 2010. 


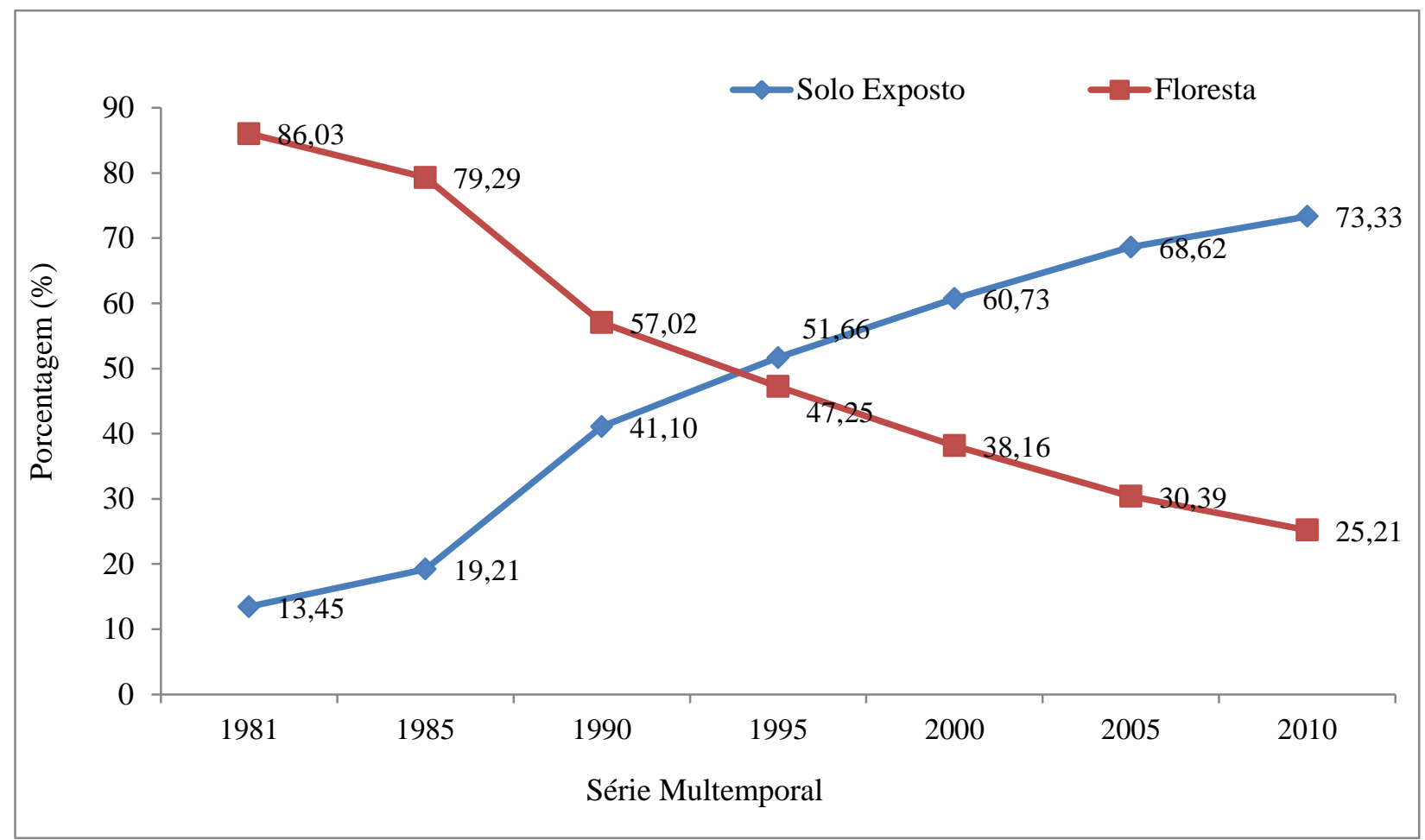

Figura 6 - Projeto Integrado de Colonização Paulo de Assis Ribeiro - PICPAR - Núcleo Inicial, Município de Colorado do Oeste. Demonstrativo da evolução da área desmatada no período de 1981 a 2010.

Para a classe pastagem registra-se um incremento em relação a 1981. Já na imagem de 1990 constata-se uma significativa redução, aspecto este verificado na década seguinte. Cunha (2010) explica que era bastante comum na época o abandono dos lotes e as frequentes desistências e deslocamento de migrantes assentados para outros PICs, em virtude da deficiência de infraestrutura interna (vias de acesso, habitação, eletrificação rural). Entre os anos de 2005 e 2010 as áreas de pastagens aumentaram veementemente em relação ao ano de 2000. Isso possivelmente deve-se a retorno e a fixação dos migrantes, aos quais pode correlaciona-se, primeiramente à valorização da pecuária, sobretudo no que se refere às exportações de carne bovina em razão do ganho de projeção cada vez maiores e, também, o aprimoramento das técnicas de pecuária associada ao confinamento, sobretudo a partir de 2000. Vale salientar que na atualidade o estado rondoniense dispõe de 12 milhões de cabeças de gado bovino e por esse motivo ocupa a sétima posição no ranking nacional (IBGE, 2013).

É importante registrar que tanto no atual Código Florestal Brasileiro (Lei no 12.651/2012) ${ }^{1}$, como no anterior consta que deve ser mantida sob a forma de reserva legal, área com cobertura florestal original de no mínimo 80\% das propriedades rurais na Amazônia.

Segundo o atual Código Florestal estas áreas somente podem ser utilizadas para manejo florestal sustentado com aprovação no IBAMA (Instituto Brasileiro do Meio Ambiente e dos

\footnotetext{
${ }^{1}$ Tanto no Código Florestal Brasileiro atual Lei ${ }^{\circ} 12.651$ como no anterior, Lei $\mathrm{n}^{\mathrm{o}} 4.771$, de 15 de setembro de 1965 , consta que para a região Amazônica a cobertura florestal original deve ser no mínimo de $80 \%$ nas propriedades rurais.
} 
Recursos Naturais Renováveis). Observando a área parcial estudada ao longo dessa série multitemporal verificou-se que só resta pouco menos que $30 \%$ da floresta natural, ou seja, $50 \%$ a menos do que o determinado para a Região Amazônica. Embora a área analisada revele que não houve o cumprimento da citada Lei, em se tratando da legislação ambiental, admitem-se indícios que futuramente outros proprietários rurais se adequem ao Novo Código Florestal e, desse modo, possam receber o rótulo de "imóvel modelo" tal qual o "Sítio Estrela" (Figura 7) cujo proprietário manteve $36.38 \%$ floresta nativa, reflorestou $31.62 \%$ e conservou $2.99 \%$ de área de preservação permanente (APP) totalizando assim, 71\% de Reserva Legal em sua propriedade (Figuras 8 e 9).

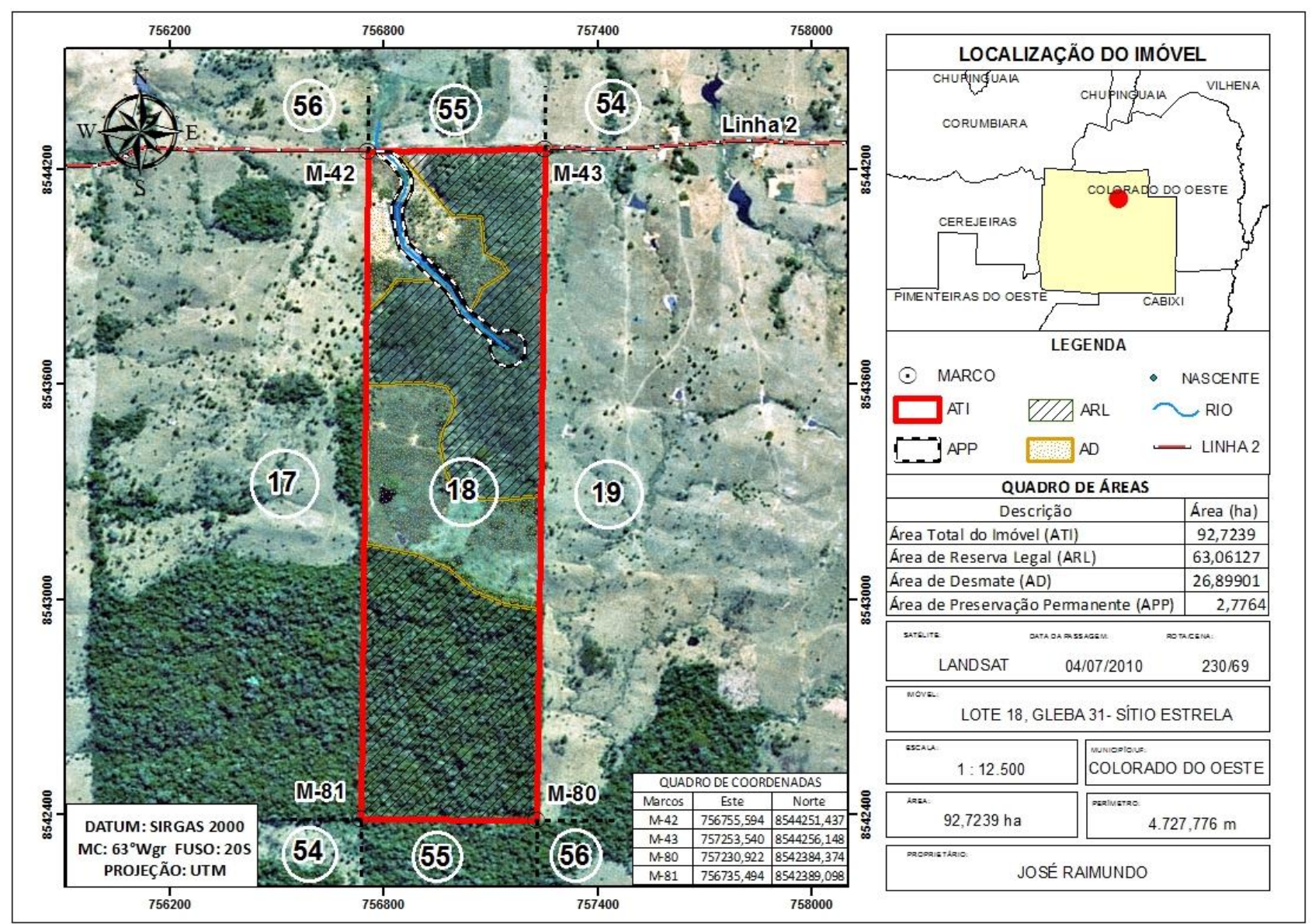

Figura 7 - Carta-imagem do sítio Estrela considerado "propriedade modelo" no núcleo inicial do Projeto Integrado de Colonização Paulo de Assis Ribeiro - PICPAR, localizado no município de Colorado do Oeste em Rondônia. Fonte: Próprios Autores. 

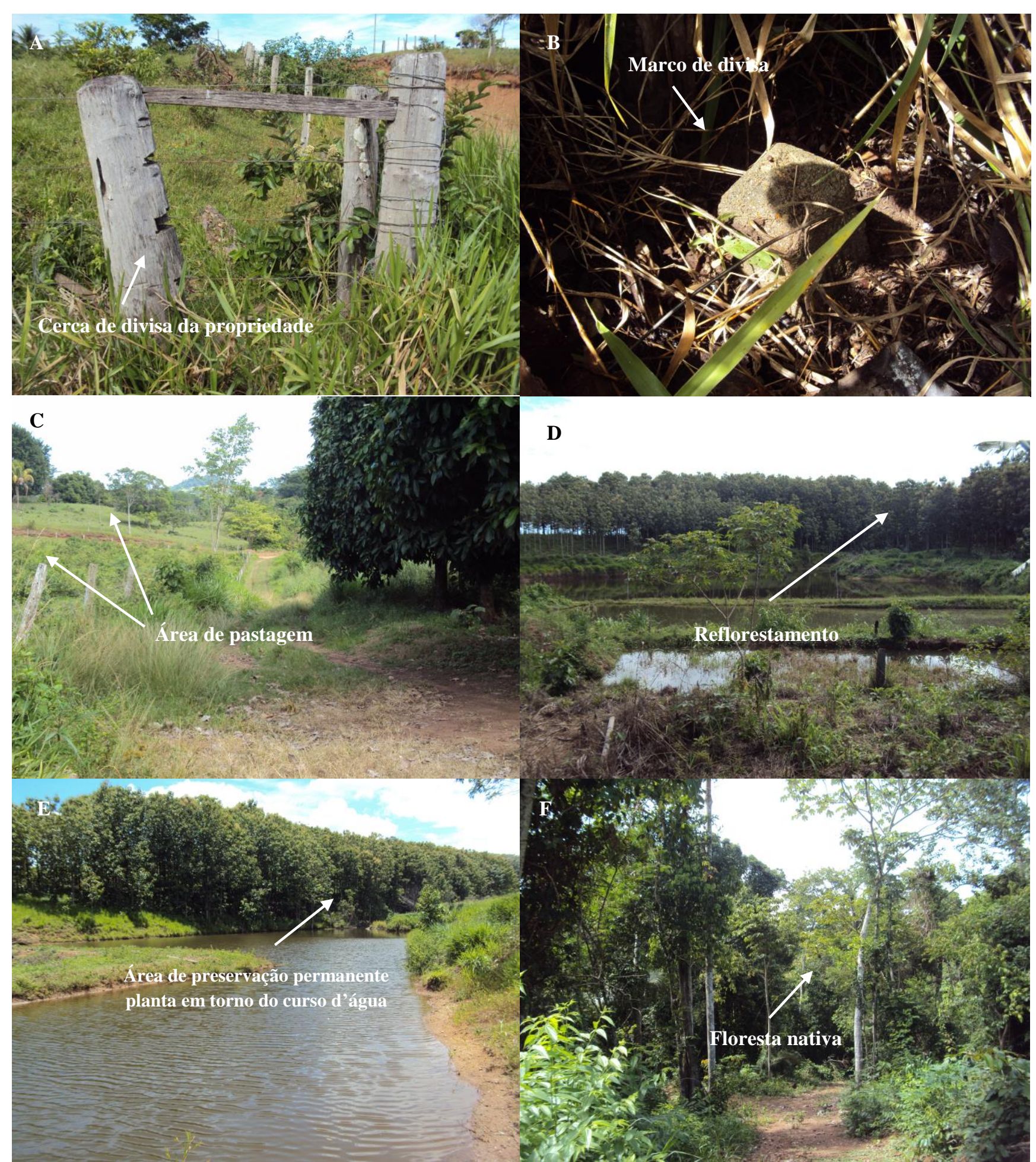

Figura 8 - Imagem ilustrando a cerca (A) e o marco de divisa (B) do sítio Estrela; o estabelecimento de áreas de pastagem que procedeu ao longo dos anos no PICPAR (C); áreas de reflorestamento (31.62\%) (D) e áreas de preservação permanente no entorno do curso d'água (E); e áreas de floresta nativa (F) (36.38\%). 

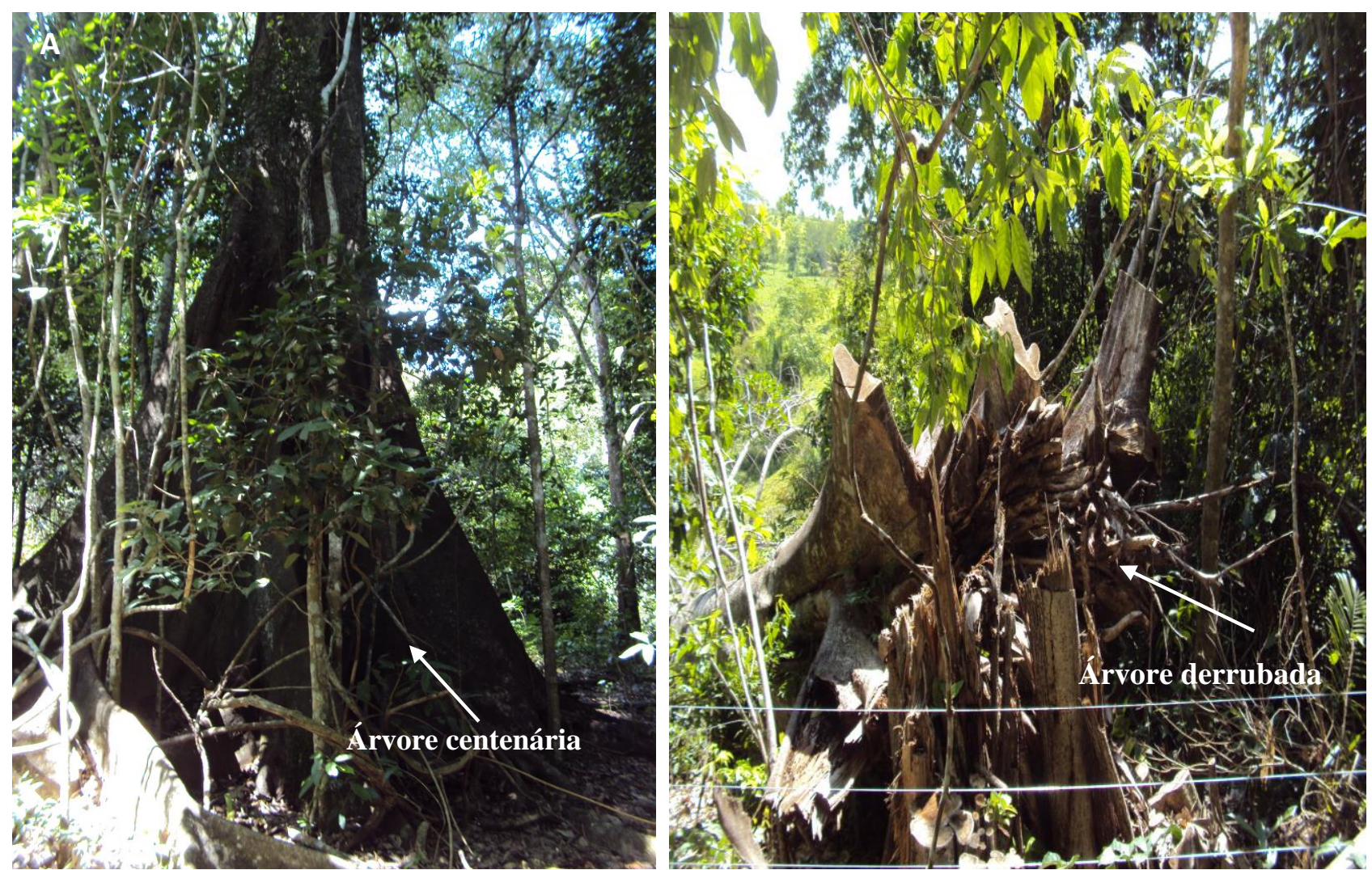

Figura 9 - Imagem ilustrando a existência de árvores centenárias na área de floresta nativa (A) e a existência da derrubada de árvores centenárias para a implantação de áreas de pastagem.

Para a classe queimada nota-se que a partir da década de 90, depois de um quinquênio de significativas queimadas as áreas com pastagem tiveram um alto incremento. De acordo com Alves et al. (2003), tal padrão pode ser justificado mediante a conversão direta da floresta em pastagem. Esse processo se inicia com cultivos anuais antes do estabelecimento da pastagem. Após alguns anos e à medida que a pastagem perde qualidade, em alguns casos adota-se à prática de repetidos ciclos de queimadas, aplicação de fertilizantes e ressemeadura; em outros, ocorre o abandono para sucessão secundária.

Um aspecto importante a considera no tocante à ampliação das áreas de pastagens se refere ao fato de que a ampliação das áreas de pastagens pode contribuir para o sequestro do carbono atmosférico, atuando para mitigar o efeito estufa e suas consequências ao meio ambiente. Estudos conduzidos na Europa demonstraram que tanto o uso de nitrogênio e o consequente aumento da taxa de lotação, e os respectivos aumentos na emissão de óxido nitroso $\left(\mathrm{N}_{2} \mathrm{O}\right)$ e metano $\left(\mathrm{CH}_{4}\right)$, potentes gases de efeito estufa, foram compensados pelo grande influxo de carbono atmosférico para o solo, configurando essas áreas de pastagens como prováveis mitigadoras do efeito estufa (SOUSSANA et al., 2007).

A percentagem de área desmatada na região estudada (Figura 5) demonstra um contínuo crescimento desde 1981 até 2010, ou seja, pode-se verificar que a dinâmica de desmatamento permanece ativa no PICPAR. Esse intenso desflorestamento pode ser atribuído à política de 
colonização da região, visto que a posse definitiva era vinculada aos colonos somente se houvesse benfeitorias nos lotes. Em outras palavras, o desmatamento era sinônimo de "benfeitoria", prática mais utilizada pelos assentados (THÉRY, 2010).

\subsection{Desempenho global e índice Kappa}

Os índices de exatidão global foram superiores a 80\% para as imagens analisadas em 1981, 1985, 1990, 1995 e 2000. Isso significa que mais de $80 \%$ das amostras foram corretamente identificadas pelo classificador, quando comparada com a imagem RGB (TM4, TM5, TM3), mostrando um bom resultado da classificação. Por outro lado, a imagem de 2010 apresentou um desempenho razoável, superior a $70 \%$.

Determinou-se o índice kappa para avaliar a exatidão dos dados, permitindo uma visualização dos resultados da classificação temática em relação à imagem RGB (TM4; TM5; TM3). O resultado indicou um coeficiente kappa excelente, ou seja, superior a $80 \%$ para as imagens classificadas dos anos de 1981, 1985 e 1990, enquanto que para as demais imagens - 1995, 2000, 2005 e 2010 - obteve-se um desempenho considerado razoável (Tabela 3).

Tabela 3 - Classificação da acurácia global e do índice kappa para os períodos considerados.

\begin{tabular}{cccc}
\hline \multirow{2}{*}{ Anos } & \multicolumn{2}{c}{ Índices } & \multirow{2}{*}{ Conceito } \\
\cline { 2 - 3 } $\mathbf{1 9 8 1}$ & Acurácia Global (\%) & Kappa & Excelente \\
\cline { 2 - 3 } $\mathbf{1 9 8 5}$ & 96,6 & 0,86 & Excelente \\
$\mathbf{1 9 9 0}$ & 90,7 & 0,83 & Excelente \\
$\mathbf{1 9 9 5}$ & 92,6 & 0,84 & Razoável \\
$\mathbf{2 0 0 0}$ & 81,3 & 0,69 & Razoável \\
$\mathbf{2 0 0 5}$ & 86,6 & 0,75 & Razoável \\
$\mathbf{2 0 1 0}$ & 92,0 & 0,78 & Razoável \\
\hline
\end{tabular}

Para Peluzio et al. (2013) esses resultados possivelmente podem estar relacionados com o predomínio de classes. Conforme visto na figura 4 constata-se o predomínio da classe floresta até 1990. Essa classe temática apresenta características de homogeneidade e, dessa forma, facilita a interpretação. Além disso, Arraes et al. (2010) apresentam em sua pesquisa resultados semelhantes (IK superior a 0,8) somente para três classes (floresta, solo exposto e não classificado) e ressaltam que incluir classes temáticas aumentam os índices de confusão, principalmente para o grupo de classes água e queimada bem como pastagem e solo exposto como foi observado nesse trabalho. Com base nisso, acredita-se que esses resultados tenham sido atingidos, tendo em vista o fato do 
índice kappa se referir a um método para avaliar a concordância ou discordância entre duas situações. Pode-se dizer que a classificação na área estudada aproximou-se razoavelmente da realidade do campo para o período considerado nessa análise multitemporal.

\section{CONCLUSÕES}

A análise qualitativa dos mapas temáticos de uso e ocupação do solo do projeto integrado de colonização Paulo de Assis Ribeiro, juntamente com as informações obtidas nos trabalhos de campo, possibilitou melhor visualização e compreensão das mudanças ocorridas no espaço geográfico ao longo dos anos, possibilitando observar o elevado grau de alteração da região.

Ao longo do período de avaliação (1981-2010), constatou-se perda de cerca de $70 \%$ da cobertura vegetal natural. Nesse processo, averiguou-se, principalmente, a conversão da floresta em pastagem.

A classificação na área estudada apresentou desempenho entre razoável e excelente $(0.58$ a 0.86) isso significa que a classificação das imagens aproximou-se razoavelmente da realidade do campo, confirmando a importância das geotecnologias nos estudos ambientais.

\section{REFERÊNCIAS}

ALVES, D. S.; ESCADA, M. I. S.; PEREIRA, J.L.G.; LINHARES, C.A. Land use intensification and abandonment in Rondônia, Brazilian Amazônia. International Journal of Remote Sensing. v.24, n.4, p. 899-903, 2003.

AZEVEDO, A. R. Análise das imagens dual multitemporais do cosmo-skymed como subsídio ao mapeamento de uso e cobertura da terra no Sul do Amazonas. São José dos Campos, 2013, $119 f$. Dissertação (Mestrado em Sensoriamento Remoto). Instituto Nacional de Pesquisas Espaciais, São José dos Campos, 2013.

AZEVEDO, A. R.; SANTOS, J.R.; GAMA, F.F.; GRAÇA, P.M.L.A.; MURA, J.C. Caracterização de uso e cobertura da terra na Amazônia utilizando imagens duais multitemporais do COSMO-SkyMed. Revista Acta Amazônica. Manaus, v. 44, p. 87 - 98, 2014.

ARRAES, C.L.; ROCHA, .M.; MORAES, R.A.; PISSARRA, T.C. T.; RODRIGUES, F.M.; ZANATA, M. Estimativa da taxa de desmatamento do município de Bannach, Pará - Amazônia Legal, utilizando imagens Landsat5/TM. Revista de Ciências Agrárias. Lisboa, v.33, n.2 p.231-243, 2010.

BRASIL. Lei $\mathrm{n}^{\circ}$ 12.651, de 25 de maio de 2012.

BRASIL. Lei n ${ }^{\circ}$ 4.771, de 15 de setembro de 1965.

CORRÊA, F.L.O.; RAMOS, J.D.; GAMA-RODRIGUES, A.C.; MÜLLER, M.W. Produção de serapilheira em sistema agroflorestal multiestratificado no estado de Rondônia, Brasil. Revista Ciência e Agrotecnologia. Lavras, v. 30, n.6, p. 1099-1105, 2006.

CUNHA, E. Cotidiano Familiar no Processo de Colonização em Rondônia: PIC Ouro Preto. Porto Velho: Universidade Federal de Rondônia, 2010. 
DAL MAGRO, E.F.; BRAGA, A.C.O.; NUNES, D.D. Dinâmica de ocupação territorial e reflexos nas águas superficiais de uma bacia hidrográfica da região amazônica. Revista Científica Internacional. Lisboa, v.3, n.13, p. $84-108,2010$.

EMPRESA BRASILEIRA DE PESQUISA AGROPECUÁRIA - EMBRAPA. Centro Nacional de Pesquisa de Solos. Sistema brasileiro de classificação de solos. 3 Ed. rev. ampl.- Brasília, DF: Embrapa Solos, p.353, 2013.

GOIS, D.V. Planejamento ambiental e o uso do geoprocessamento no ordenamento da bacia hidrográfica do rio da Dona, Bahia - Brasil. Aracaju, 2010, 305f. Tese (Doutorado em Geografia). Universidade Federal de Sergipe, Aracaju, 2010.

HOFF, R.; VACCARO, S.; KROB, A.J.D.. Aplicação de geotecnologias — detecção remota e geoprocessamento - para a gestão ambiental dos recursos hídricos superficiais em Cambará do Sul, RS, Brasil. Revista de Estudos Politécnicos. v. 6, p. 103-127, 2008.

Instituto Brasileiro de Geografia e Estatística, IBGE. Estatística da Produção Pecuária - Indicadores do IBGE. Dispponível em: <http://http://www.ibge.gov.br> Acesso em 06 mar de 2014.

Instituto Nacional de Pesquisas Espaciais, INPE. Catálogo de imagens LANDSAT (online). Instituto Nacional de Pesquisas Espaciais (INPE). São José dos Campos, São Paulo, Brasil. Disponível em: <http://www.inpe.br/>Acesso em 14 dez de 2013.

LATORRE, M.L.; JUNIOR, O.A.C.; SANTOS, J.R.; SHIMABUKURO, Y.E. Integração de dados de sensoriamento remoto multi resoluções para a representação da cobertura da terra utilizando campos contínuos de vegetação e classificação por árvores de decisão. Revista Brasileira de Geofísica. São Paulo, v.25, n.1, p 63-74, 2007.

LIMA, A.A.; SILVA, H.S.; SANTOS, C.H.; MENDONÇA, J.L. Desempenho e produtividade de genótipos de cebola em argissolo na região sul de Rondônia. Revista Brasileira Agrociência. Pelotas, v.17, n. 2-4, p.185-192, 2011.

LISBOA, F.T. A colonização em Rondônia e o meio ambiente. Revista Partes Online. Disponível em: http://www.partes.com.br/> Acesso em: 19 jan2013.

OKA-FIORI, C.; PIO FIORI, A.; HASUI, Y.. Dinâmica da ocupação do solo da bacia do rio Itiquira, Mato Grosso, Brasil. Revista RAEGA. Curitiba, n. 7, p. 19-31, 2003.

MARTINS, T.I.S.; RODRIGUES, S.C. Ocupação e uso da terra na bacia do médio-baixo curso do rio Araguari/MG. Revista Boletim de Geográfia. Maringá, v. 30, n.1, p. 55-68, 2012.

MOSER, L.M. A Mulher Na Colonização: O Papel Da Mulher No PIC-Ouro Preto em Rondônia, Pará: Núcleo de Altos Estudos Amazônicos/ NAEA, 2008. Disponível em:<http://www.ufpa.br>. Acesso em 06 jan de 2014.

PELUZIO, T.M.O.; SANTOS, A.R.; FIEDLER, N.C.; BAUER, M.O.; GARCIA, G.O.; SIMÃO, J.B.P.; PELUZIO, JB.E. Comparação fotointerpretativa entre aerofoto e imagem de satélite. Revista Ciência Florestal. Santa Maria, v. 23, n.2, p. 537-544, 2013.

RABELLO, A.C.; FERREIRA, L.F. Colonização do sudoeste da Amazônia Corumbiara/RO (1975-2005).In: Simpósio Nacional de História. 23., 2005, Londrina. Anais...Londrina. p.1-7.

RIBEIRO, L.S. Análise qualitativa e quantitativa de erosão laminar no município de Campos dos Goytacazes/RJ através de técnicas de geoprocessamento. Campos dos Goytacazes, 2006, 158f. Dissertação (Mestrado em Engenharia Civil). Universidade Estadual do Norte Fluminense, Campos dos Goytacazes, 2006. 
ROSOT, M.A.D.; GARRASTAZÚ, M.C.; OLIVEIRA, Y.M.M. Sistemas de Informações Geográficas (SIG) como subsídio para a elaboração de planos de manejo em fazendas experimentais. Colombo, PR. Embrapa Florestas, dez. 2008. 6 p. (Embrapa Florestas. Comunicado Técnico, 216). ISSN 1517-5030.

ROSA, R.. Geotecnologias na Geografia Aplicada. Revista do Departamento de Geografia, Uberlândia, v. 16, p. 81-90, 2005.

ROCHA, G.M.; ROCHA, E.C.; CANTO, J.L.; PEREIRA, P.C. Avaliação de impactos ambientais nos países do Mercosul. Revista Ambiente \& Sociedade, v. 3, n.2, p. 147- 162, 2005.

SOARES-FILHO, B.S.; . NEPSTAD, D.C.; CURRAN, L.; CERQUEIRA, G.C.; GARCIA, R.A.; RAMOS, C.A.; VOLL, E.; MCDONALD, A.; LEFEBVRE, P.; SCHLESINGER, P, MCGRATH, D. Cenários de desmatamento para a Amazônia. Estudos Avançados. v. 19, n. 54. p. 137-152, 2005.

SOUSSANA, J. F.; ALLARD, V.; PILEGAARD, K.; AMBUS, P.; AMMAN, C.; CAMBELl, C.; CESCHIA, E.; CLIFTON-BROWN, J.; CZOBEL, S.; DOMINGUES, R.; FLECHARD, C.; FUHRER, J.; HENSEN, A.; HORVATH, L.; JONES, M.; KASPER, G.; MARTIN, C.; NAGY, Z.; NEFTEL, A.; RASCHI, A.; BARONTI, S.; RESS, R.M.; SKIBA, U.; STEFANI, P.; MANCA, G.; SUTTON, M.; TUBA, Z.; VALENTINI, R. Full accounting of the greenhouse gas $\left(\mathrm{CO}_{2}, \mathrm{~N}_{2} \mathrm{O}, \mathrm{CH}_{4}\right)$ budget of nine European grassland sites. Agriculture, Ecosystemsand Environment, v.121, n.1-2, p. 121-134, 2007.

THÉRY, H. Estradas e desmatamento na Amazônia brasileira: Rondônia 1974-1996. Revista M@ppemonde.v.97, n.3, p. 35-40, 1997.

THÉRY, H. Rondônia mutações de um território federal na amazônia brasileira. Paris, 2010, 238f. Tese (Doutorado em Geografia). Universidade de Paris I, Paris, 2010. 